\title{
O PAPEL DO ADESIVO DE FIBRINA E DA SUTURA NA FIXAÇÃO DO TRANSPLANTE DE MENISCO PRESERVADO POR ULTRACONGELAMENTO EM COELHOS
}

\author{
THE ROLE OF FIBRIN GLUE AND SUTURE ON THE FIXATION OF ULTRA \\ FROZEN PRESERVED MENISCUS TRANSPLANTATION IN RABBITS
}

Leandro José Reckers', Djalma José Fagundes², José Luiz Pozo Raymundo ${ }^{3}$, Geraldo Sérgio de Mello Granata Júnior4, Márcia Bento Moreira ${ }^{5}$, Vanessa Carla Paiva ${ }^{6}$, Anna Luiza Negrini Fagundes ${ }^{7}$, Moises Cohen ${ }^{8}$

\section{RESUMO}

Objetivo: Avaliar a capacidade do adesivo de fibrina em promover a fixação do menisco ao longo de duas, quatro e oito semanas comparando com a técnica convencional de fixação por sutura a tecidos moles. Métodos: 36 meniscos mediais direitos de coelhos preservados a $73^{\circ} \mathrm{C}$ negativos por 30 dias foram transplantados para os animais da mesma amostra e fixados com sutura ou cola de fibrina. Após duas, quatro ou oito semanas a aparência dos meniscos e a qualidade da fixação foram verificadas macroscopicamente e avaliadas por um sistema de escores. Os achados foram submetidos a estudo estatístico de análise de variância por postos ( $\mathrm{p} \leq 0,05 \%)$. Resultados: A preservação por ultracongelamento manteve a integridade macroscópica dos meniscos transplantados. Após todos os períodos pós-transplante também não houve redução significante da extensão dos meniscos $(p=0,015)$. Os meniscos fixados com fibrina mostraram discretas alterações de coloração e rugosidade de superfície. Não houve sinais de rejeição ou infecção em ambos os grupos. A avaliação por escores da fixação pela sutura foi superior $(p=0,015)$ em todos os períodos (80\% de fixação total) do que a fixação promovida pela fibrina (20\% de fixação total). Conclusão: O transplante homólogo do menisco de coelho sofreu diferentes graus de integração ao joelho de acordo com a técnica de fixação; a técnica operatória com sutura aos tecidos moles mostrou-se superior na avaliação de escores em relação à fixação com adesivo de fibrina.

Descritores - Menisco; Transplante; Coelhos; Adesivo tecidual de fibrina

\section{ABSTRACT}

Objective: To evaluate the ability of fibrin adhesive in promoting the meniscus fixation within two, four and eight weeks compared to the conventional soft-tissue suture technique. Materials and Methods: 36 right medial menisci of rabbits preserved at negative $73^{\circ}$ Celsius for 30 days were transplanted to animals of the same sample and fixed with soft-tissue suture or fibrin glue. After 2, 4 or 8 weeks, the appearance of the menisci and the quality of fixation were macroscopically checked and evaluated by a scoring system. The findings were subjected to the statistical study of variance analysis ( $p \leq 0.05 \%)$. Results: The deep-frozen meniscus preservation maintained the integrity of the meniscus transplant, and, macroscopically, there was no significant reduction of the length of the meniscus in all posttransplant periods ( $p=0.015$ ). The menisci fixed with fibrin showed slight changes in color and surface roughness. There were no signs of rejection or infection in both groups. Suture fixation scoring was superior $(p=0.015)$ in all periods $(80 \%$ of total fixation) as compared to the setting promoted by fibrin (20\% of total fixation). Conclusion: The homologous transplantation of the meniscus of rabbits experienced various degrees of integration to the knee according to the fixation method; the surgical soft tissues suturing technique was shown to be superior in the evaluation of scores compared to the fixation with fibrin adhesive.

Keywords - Meniscus; Transplantation; Rabbits; Fibrin tissue adhesive

1 - Doutor em Ciências pela Universidade Federal de São Paulo-Unifesp, São Paulo, Brasil.

2 - Professor Associado e Livre-Docente do Departamento de Cirurgia da Universidade Federal de São Paulo-Unifesp, São Paulo, Brasil.

3 - Doutor em Ciências pela Universidade Federal de São Paulo-Unifesp; Professor Adjunto do Departamento de Ortopedia da Universidade Federal de Pelotas, Brasil.

4 - Mestre em Ciências pela Universidade Federal de São Paulo-Unifesp, São Paulo, Brasil.

5 - Médica Veterinária; Doutora em Ciências pela Universidade Federal de São Paulo- Unifesp, São Paulo, Brasil.

6 - Médica Veterinária; Mestre em Ciências pela Universidade Federal de São Paulo, Unifesp, São Paulo, Brasil.

7 - Acadêmica de Medicina. Universidade de Santo Amaro-Unisa, São Paulo, Brasil.

8 - Professor Associado e Livre-Docente do Departamento de Ortopedia da Universidade Federal de São Paulo-Unifesp, São Paulo, Brasil.

Correspondência: Rua Gonçalves Chaves, 3.500, ap: 302 - 96015-560 - Pelotas - Brasil. E-mail: leandroreckers@uol.com.br 


\section{INTRODUÇÃO}

As lesões de meniscos, que necessitam de meniscectomia parcial ou total, estão relacionadas, em maior ou menor grau, em curto ou longo prazo, com a degeneração da articulação do joelho representada pelos diversos graus de osteoartose ${ }^{(1-9)}$.

O transplante de menisco é uma opção entre as diversas propostas de tratamento. A reposição do menisco lesado por outro homólogo é uma proposição testada há décadas; contudo, alguns aspectos do procedimento ainda são controversos e merecem a atenção dos pesquisadores. A fixação do menisco apresenta um grau de dificuldade técnica que é um fator de limitação importante do procedimento, principalmente após o advento da cirurgia videoassistida ${ }^{(10-20)}$.

Nesse contexto, o uso de uma substância adesiva que possa fixar o menisco transplantado seria um avanço na diminuição do tempo do procedimento, na facilidade de sua realização e na recuperação do paciente ${ }^{(21)}$.

A fibrina é uma substância com propriedades adesivas que tem sua aplicação consagrada em outros tecidos e órgãos. É um produto derivado de plasma humano e que vem sendo utilizada em escala cada vez maior como um adesivo tecidual biodegradável. Sua aplicação em diversas situações cirúrgicas busca diminuir ou impedir os sangramentos em estruturas parenquimatosas ou proporcionar a aproximação continente de estruturas tubulares ${ }^{(22-23)}$.

O mecanismo de ação desse adesivo é explicado por uma reação cruzada com o fator XIII da coagulação, tendo o cálcio como catalisador, o que faz com que a trombina converta o fibrinogênio em uma rede firme de fibrina que é mecanicamente estável e com acentuadas propriedades adesivas ${ }^{(24-27)}$.

O coelho é relatado com frequência na literatura como modelo animal de experimentação em transplante de meniscos ${ }^{(8,9,13,14,27)}$. No presente projeto estabeleceu-se o procedimento do uso de meniscos homólogos ultracongelados de coelhos que foram transplantados para diferentes animais após 30 dias de preservação, simulando condição que pode ser encontrada em casos clínicos com humanos.

A proposta desta pesquisa foi avaliar a capacidade do adesivo de fibrina em promover a fixação do menisco ao longo do tempo (duas, quatro e oito semanas) comparando com a técnica convencional de fixação por sutura.

\section{MÉTODOS}

O experimento foi submetido à apreciação e aprovação do Comitê de Ética em Pesquisa da Universida- de Federal de São Paulo-Unifesp-EPM (protocolo ${ }^{\circ}$ 238/03). Todos os procedimentos seguiram estritamente as normas do Colégio Brasileiro de Experimentação Animal (Cobea).

\section{AMOSTRA}

Foram utilizados 36 coelhos (Oryctolagus cuniculus), da linhagem Nova Zelândia, albinos, machos, com idade entre seis e oito meses e peso médio de 3.250 gramas.

Os coelhos foram alojados no Biotério da Disciplina de Técnica Operatória e Cirurgia Experimental da Unifesp-EPM, alojados em gaiolas individuais, em condições de temperatura controlada por sistema de arcondicionado, ciclo de luz-escuridão de 12 horas e alimentação com ração própria para a espécie e com água à vontade. $\mathrm{O}$ estudo foi dividido em três etapas, realizadas durante um período de 12 meses.

\section{Procedimento anestésico}

Os animais foram pesados em balança de precisão, imediatamente antes da medicação pré-anestésica para cálculo das doses de anestésicos.

Previamente a anestesia, foi realizada a profilaxia antimicrobiana com penicilina procainada (Laboratório Ariston $^{\circledR}$, São Paulo, SP) na dose $40.000 \mathrm{U} / \mathrm{kg}$ dia, mantido com uma dose diária por mais dois dias após o procedimento.

Na sala operatória os coelhos receberam como medicação 2,4mg/kg de acepromazina (Acepran ${ }^{\circledR}$, Univet, São Paulo, SP ) a 1\% e 4mg/kg de cloridrato de xilazina (Anasedan $^{\circledR}$, Vetbrands, São Paulo, SP) adicionados na mesma seringa e administrados pela via intramuscular (região posterior da coxa - ventre dos músculos semitendíneo e semimembranáceo).

Viabilizou-se um acesso venoso por meio da punção da veia auricular marginal, para infusão de solução salina de cloreto de sódio a 0,9\% e das drogas necessárias para a indução anestésica como cloridrato de quetamina (Ketalar $^{\circledR}$, Parke-Davis, São Paulo, SP) e cloridrato de xilazina (Rompun ${ }^{\circledR}$, Bayer, São Paulo, SP), na proporção de $1: 1$, administrando-se $0,5 \mathrm{ml}$ dessa solução.

Os animais foram mantidos em decúbito dorsal na calha operatória e intubados com sonda orotraqueal 2,5 sem balão. A manutenção anestésica se fez com isofluorano (AstraZeneca, São Paulo, SP) a 1,5\%, em fluxo constante de 2L por minuto e com frequência respiratória de dez movimentos respiratórios por minuto, ciclados pelo aparelho Takaoka ${ }^{\circledR}$ (modelo KT12 Sansei). 


\section{Procedimento operatório no doador}

Com o animal anestesiado foi realizada a tricotomia de todo o membro posterior direito, desde a raiz da coxa até a pata do animal, sem incluí-la. Antissepsia com solução de polivinilpirrolidona (Povidine ${ }^{\circledR}$, São Paulo, SP) e colocação de panos esterilizados delimitando o campo operatório. Incisão longitudinal parapatelar medial de $4 \mathrm{~cm}$ interessando pele e tela subcutânea; identificouse o ligamento da patela e expôs-se a cápsula articular medial. Um esforço em valgo e flexão do joelho foram o suficiente para acessar o menisco medial. A meniscectomia total foi realizada com um bisturi lâmina . $^{\circ}$ 15 e uma tesoura reta de $10 \mathrm{~cm}$. Fechamento da cápsula articular e pele com pontos separados foi realizado com fio de poliamida 5.0 (Mononylon ${ }^{\circledR}$ - Ethicon). Terminado o ato operatório, o animal foi levado para a sala de recuperação e observado por um período pós-anestésico até a recuperação total da consciência e deambulação espontânea, tendo posteriormente retornado ao alojamento do Biotério.

\section{Preservação dos meniscos}

Após sua retirada, os meniscos foram medidos em seu eixo maior e colocados em pequenos sacos de plástico estéreis $(4 \times 3 \mathrm{~cm})$ e lacrados com fita adesiva estéril. Cada conjunto foi colocado em outro invólucro cilíndrico de plástico rígido ( $5 \mathrm{~cm}$ de diâmetro) previamente esterilizado com óxido de etileno. O menisco foi identificado e levado para o congelador (temperatura de $73^{\circ} \mathrm{C}$ negativos), onde permaneceu por 30 dias.

\section{Procedimento de preparo do menisco para implante}

Os meniscos foram retirados do congelador e dos invólucros em que se mantinham armazenados e colocados em um recipiente com solução salina de cloreto de sódio a 0,9\% em temperatura ambiente, ocorrendo seu descongelamento em 15 minutos, em média.

\section{Procedimento operatório no receptor}

Reproduziram-se as etapas semelhantes ao primeiro procedimento operatório, (anestesia, profilaxia antimicrobiana, assepsia e antissepsia). A incisão longitudinal parapatelar medial medindo $4 \mathrm{~cm}$ foi realizada sobre a cicatriz anterior. Foi divulsionada a tela subcutânea até a exposição da cápsula articular medial. Após randomização para escolha de uma das duas técnicas, o menisco descongelado foi implantado no coelho receptor.

\section{Técnica operatória de sutura}

Foram realizados três pontos de fixação com fio de poliamida monofilamentar 5.0 (Mononylon ${ }^{\circledR}$ Ethicon), sendo o primeiro na região do corno posterior, junto à inserção do ligamento cruzado anterior na tíbia; o segundo ponto de fixação foi realizado na região do corno anterior junto à cápsula anterior; e o terceiro ponto de fixação, no corpo do menisco, onde foi realizado um ponto em "U", junto ao ligamento colateral tibial.

\section{Técnica operatória com o adesivo de fibrina}

Foi realizada a fixação do menisco com a colocação de $0,4 \mathrm{ml}$ de cola de fibrina na porção tibial do menisco medial. Realizou-se compressão manual sobre o menisco na região do platô tibial durante dois minutos, até a completa polimerização do adesivo.

\section{Critérios de avaliação macroscópica}

Após a abertura da articulação do joelho, o menisco foi exposto e avaliado na sua aparência macroscópica quanto à coloração, brilho e presença de secreção. A seguir, foi determinada a qualidade da fixação por um sistema de escore (Tabela 1).

Tabela 1 - Escores e critérios estabelecidos para avaliação macroscópica da fixação dos meniscos nos diversos tempos de observação

\begin{tabular}{c|c|l}
\hline Escore & Fixação & \multicolumn{1}{c}{ Critérios } \\
\hline $\mathbf{0}$ & Total & $\begin{array}{l}\text { Fixação total do menisco à membrana sinovial: corno } \\
\text { anterior, corpo e corno posterior }\end{array}$ \\
\hline $\mathbf{1}$ & Parcial & $\begin{array}{l}\text { Fixação parcial do menisco à membrana sinovial: apenas um } \\
\text { dos cornos fixos: corno anterior, corpo ou corno posterior }\end{array}$ \\
\hline $\mathbf{2}$ & Não fixação & Nenhum dos cornos fixos à membrana sinovial \\
\hline
\end{tabular}

\section{Estudo estatístico}

As variáveis foram representadas por média e desvio padrão (dp). Adotou-se o nível de significância de 0,05 $(\alpha \leq 5 \%)$; níveis descritivos ( $p$ ) inferiores a esse valor foram considerados significantes e representados por um asterisco.

Os grupos de diferentes métodos de fixação foram comparados dentro de cada experimento, definidos pelo tempo de eutanásia, duas, quatro e oito semanas de experimento. Foram aplicados os testes estatísticos: comparações múltiplas de Dunn, prova de Kruskal-Wallis, exato de Fisher e correção de Bonferroni ao nível de 
significância. quando um teste foi utilizado várias vezes, de forma a garantir em cada comparação de grupos um nível de significância global de 5\%.

\section{RESULTADOS}

Os meniscos fixados pela sutura apresentaram, em qualquer dos tempos estudados, aparência branco-nacarada com superfície lisa e brilhante, sem sinais que indicassem algum sofrimento de rejeição ou de processo inflamatório. Não houve a presença de qualquer tipo de secreção (Figuras 1, 2 e 3).

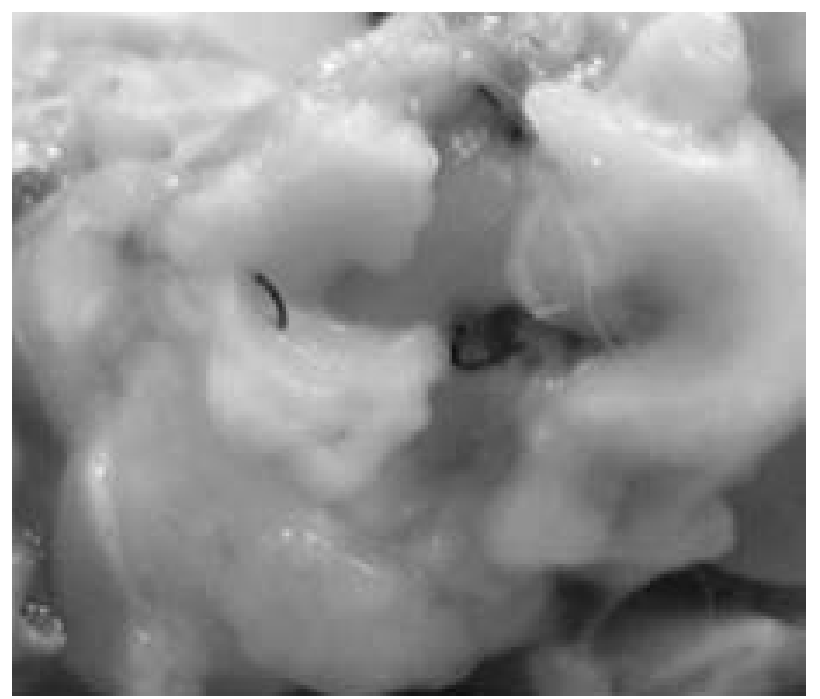

Figura 1 - Menisco suturado após duas semanas (esquerda). Notar a superfície brilhante, branco-nacarada e a ausência de secreção. Embora com discretas alterações das bordas, o seu aspecto é muito semelhante ao do menisco lateral normal (direita)

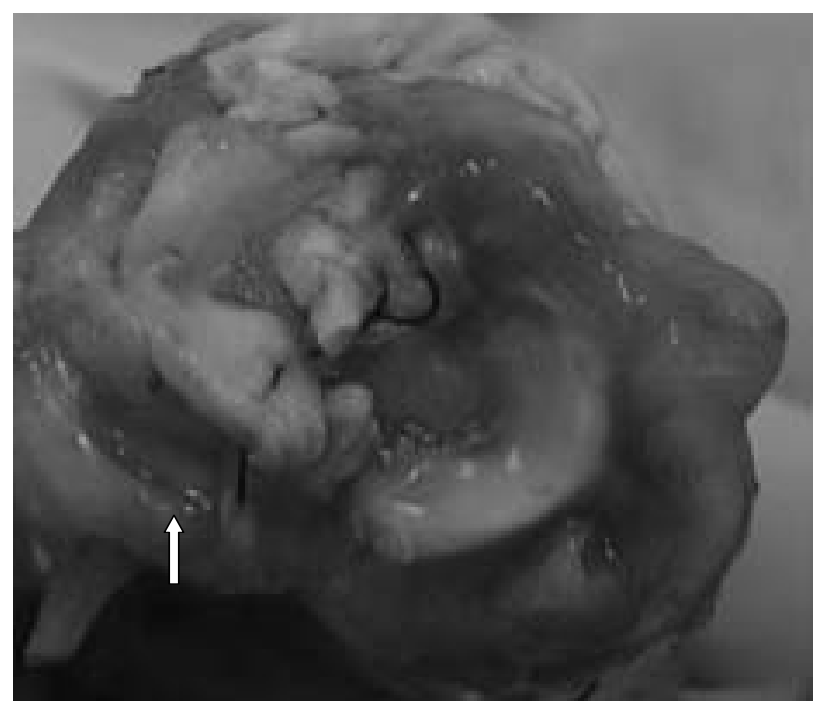

Figura 2 - Menisco suturado após quatro semanas (esquerda). Notar a superfície brilhante, branco-nacarada e a ausência de secreção. A borda do corno anterior apresenta-se descolada do platô tibial, caracterizando fixação parcial (seta)

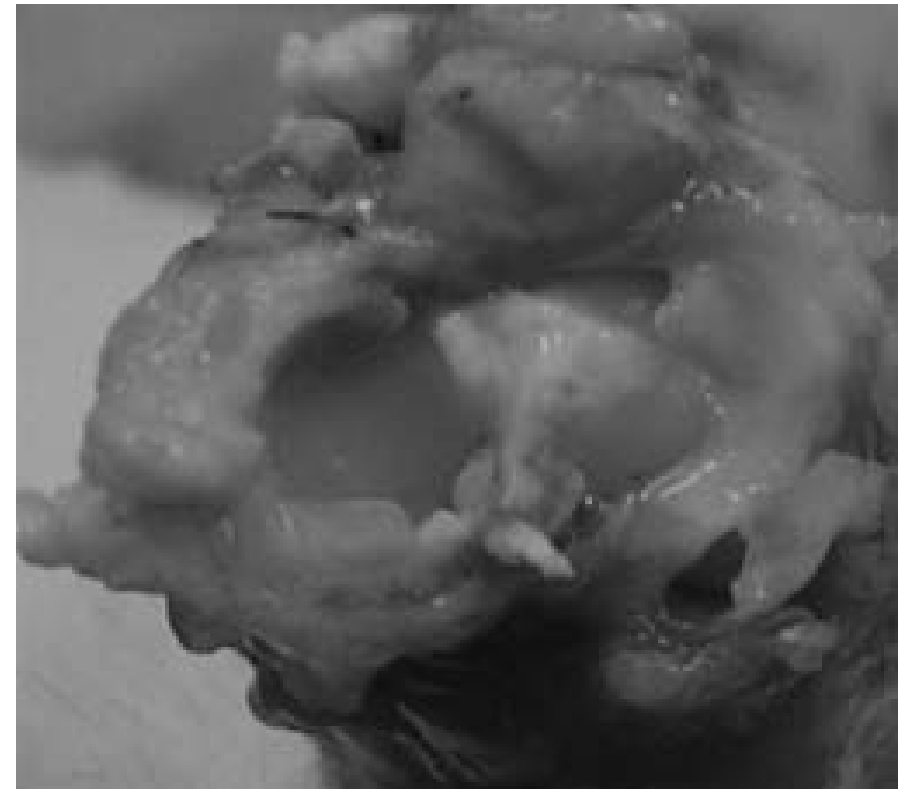

Figura 3 - Menisco suturado após oito semanas (esquerda). Notar a superfície brilhante, branco-nacarada e a ausência de secreção. A superfície e bordas apresentam leves irregularidades, porém, o menisco está firmemente fixado ao platô tibial

Já os meniscos que foram fixados pela fibrina mostraram-se com superfície irregular, coloração levemente amarelada, recobertos por fina camada de secreção amarelo-claro e opacificada. Não houve sinais compatíveis com rejeição ou necrose (Figuras 4, 5 e 6).

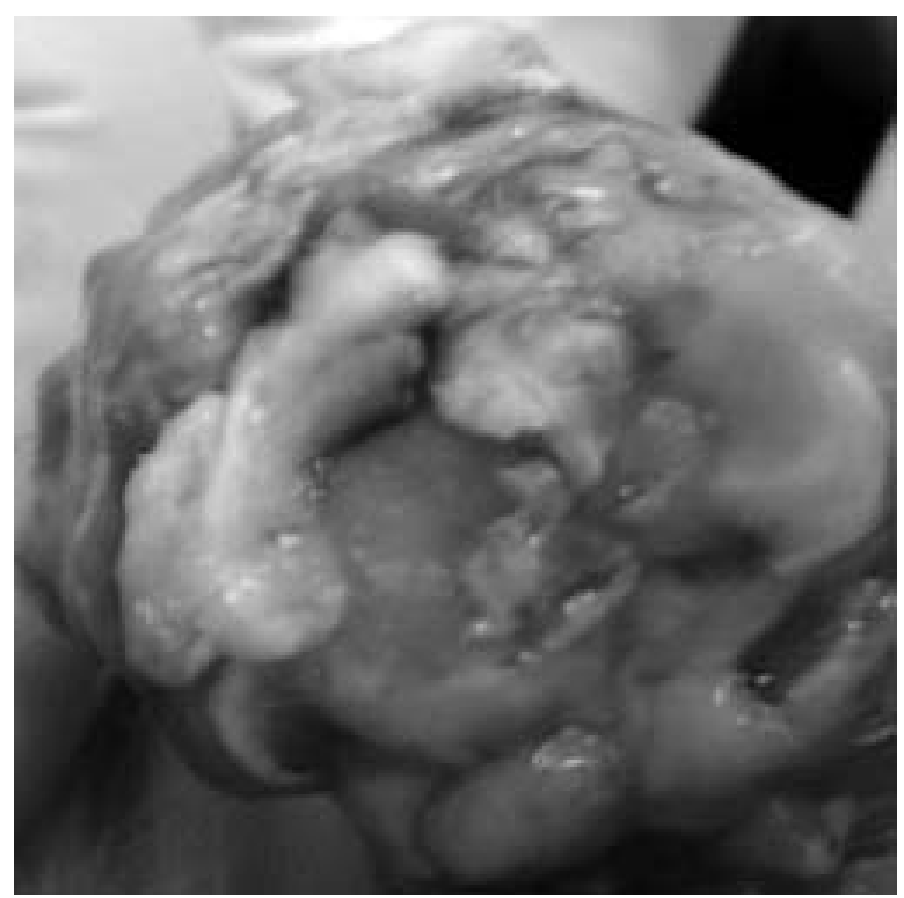

Figura 4 - Menisco fixado com fibrina após duas semanas (esquerda). Notar a superfície opaca, com superfície irregular e alterações das bordas. O seu aspecto é diferente do menisco lateral normal (direita) 


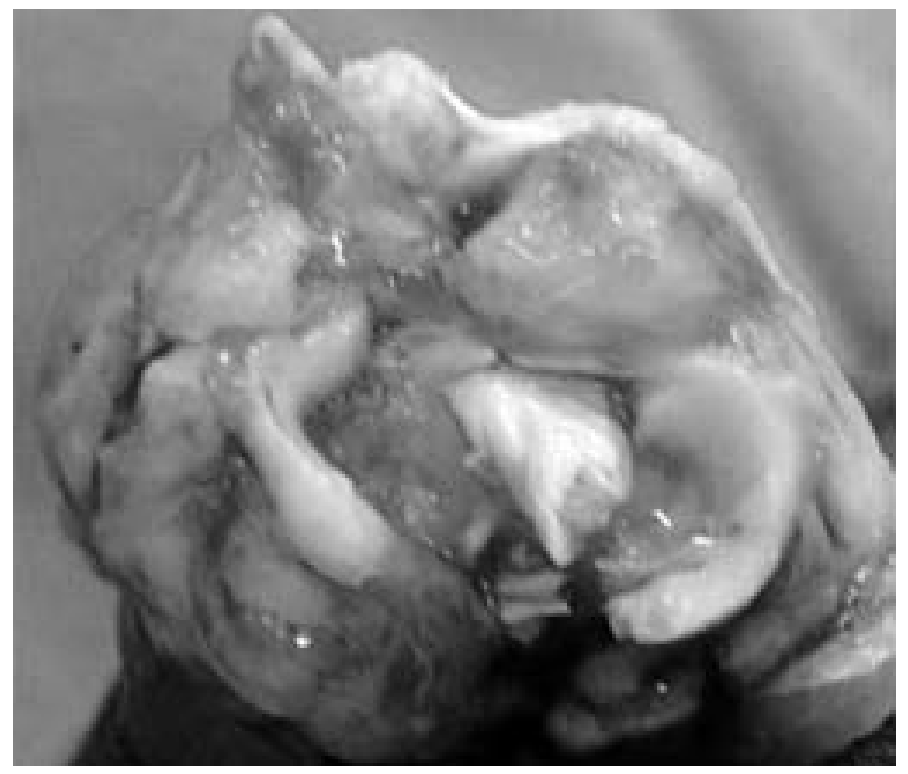

Figura 5 - Menisco fixado com fibrina após quatro semanas (esquerda). A borda do corno anterior apresenta-se descolada do platô tibial, atingindo mais da metade do corpo do menisco, caracterizando não fixação

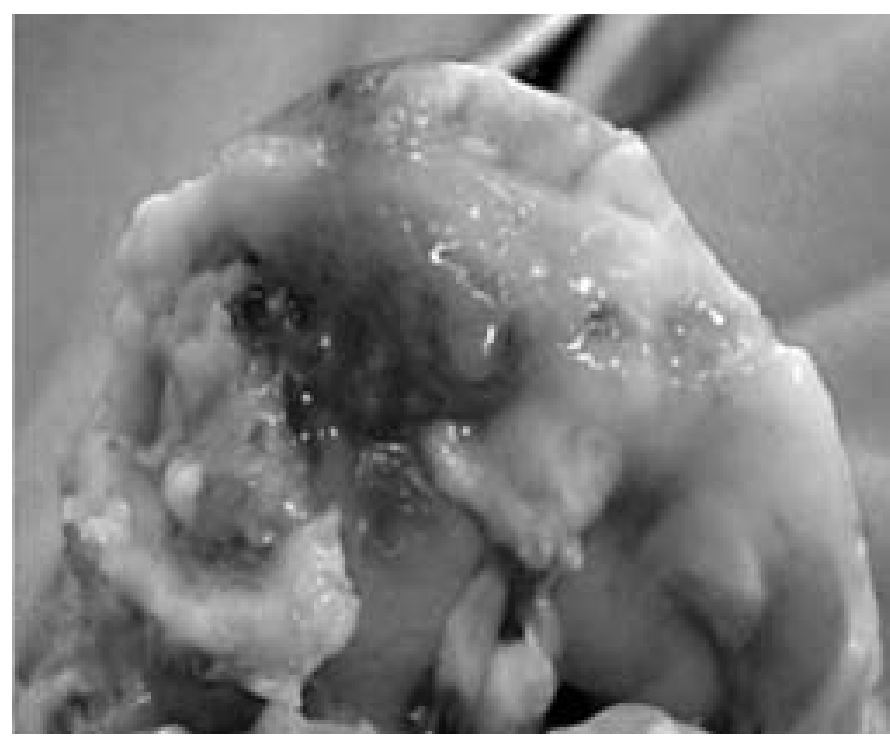

Figura 6 - Menisco fixado com fibrina após oito semanas (esquerda). O menisco está solto e deslocado

A distribuição dos meniscos quanto à porcentagem de fixação parcial (Figura 7) e total (Figura 8) mostrou diferenças significantes do ponto de vista estatístico $(\mathrm{p} \leq 0,015)$, tanto para comparação dentro dos grupos (sutura x fibrina), como entre os grupos $\left(2 .^{\mathrm{a}}, 4 .^{\mathrm{a}}\right.$ e $8 .^{\mathrm{a}}$ semana). A sutura foi mais eficaz para promover a fixação em todos os tempos de observação. $O$ adesivo de fibrina praticamente é ineficaz para promover a fixação, pois grande porcentagem dos meniscos esteve parcial ou totalmente não fixado.
Fixação Parcial do Transplante de Menisco

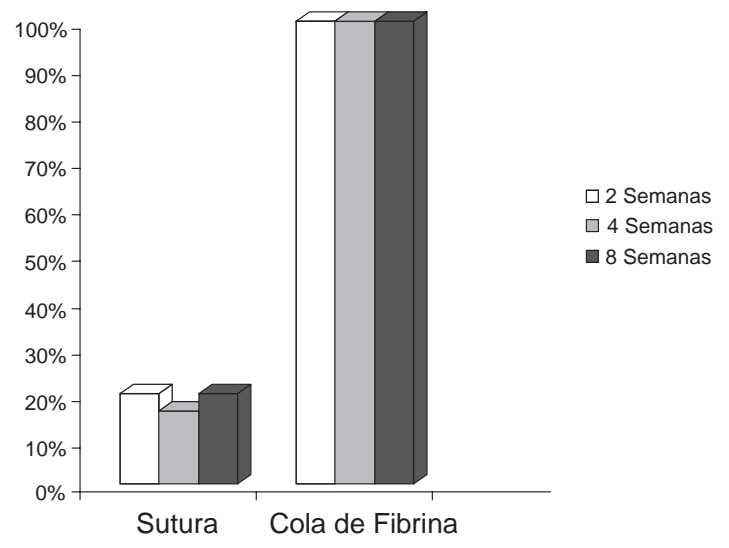

Figura 7 - Distribuição das porcentagens dos meniscos na segunda, quarta e oitava semanas de observação, segundo os critérios de fixação parcial

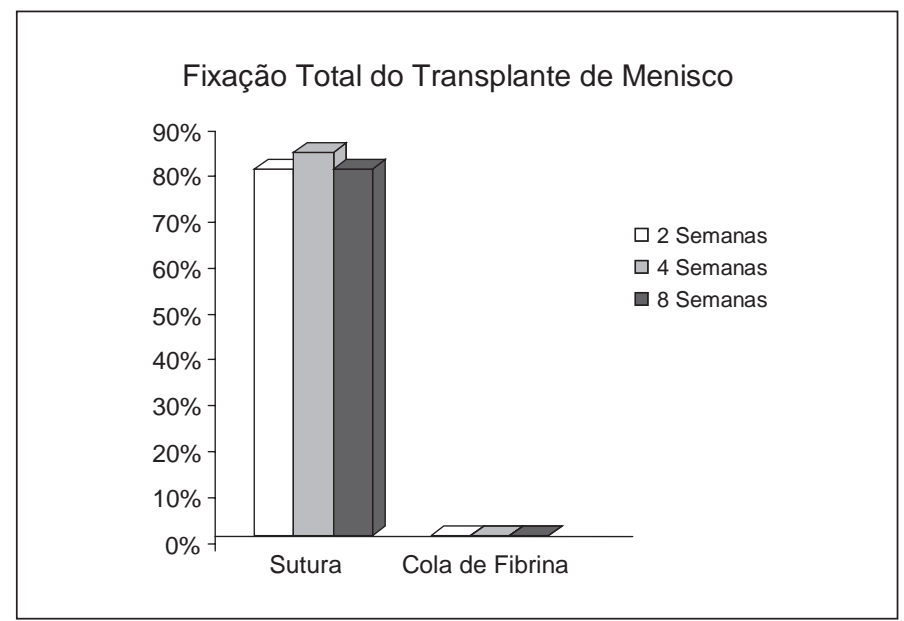

Figura 8 - Distribuição das porcentagens dos meniscos na segunda, quarta e oitava semanas de observação, segundo os critérios de fixação total

\section{DISCUSSÃO}

A tentativa de restabelecer a biomecânica do joelho e de prevenir a subsequente degeneração articular é a base racional que norteia a proposta de um transplante homólogo. A avaliação clínica da efetividade dos transplantes meniscais envolve alguns obstáculos ainda não devidamente transpostos, como a diversidade na seleção dos pacientes, as diferentes técnicas operatórias empregadas e os diversos critérios de avaliação pós-operatória. Além do mais, o quanto a restauração da dinâmica articular próxima da normal, proporcionada pelo transplante, possa prevenir a degeneração articular não está estabelecida. Trabalho ${ }^{(28)}$ com seguimento de 20 anos de transplante de menisco mostrou que alguns pacientes isolados 
apresentaram resultados subjetivos satisfatórios, mas é preciso encarar o fato de que os resultados radiográficos mostram claramente que, em longo prazo, o transplante de menisco medial não protegeu a articulação do joelho das mudanças degenerativas. Contudo, os resultados são de difícil interpretação. Uma conclusão definitiva de que o transplante não protege contra artrite não pode ser embasada apenas em uma série de $\operatorname{casos}^{(28)}$.

Assim, a experimentação animal é uma opção para se testar o transplante dentro de limitações estritas permitidas por um modelo experimental. O transplante de meniscos tem sido investigado em vários animais, como ovelhas, cães, cabras e coelhos ${ }^{(8,9,13,14,19,26)}$. A escolha do coelho foi, pois, baseada nos relatos frequentes da literatura que o referem como adequado para o estudo de transplantes de meniscos. O menisco do animal apresenta um padrão histológico muito semelhante ao encontrado em seres humanos, caracterizado por um tecido fibrocartilaginoso entrelaçado por fibras colágenas interpostas por fibrocondrócitos ${ }^{(8,9,13,14,22,27)}$. No entanto, a sua dimensão, cerca de $1 \mathrm{~cm}$, requer uma técnica delicada para dissecção, retirada, armazenamento e reimplante. Também pelas diminutas dimensões do platô tibial não foi possível testar a técnica de túneis com blocos ósseos.

Há três procedimentos de uso corrente disponíveis para a preservação dos meniscos para transplantes, como a criopreservação, a liofilização e o ultracongelamento em temperatura inferior a $70^{\circ} \mathrm{C}$ negativos. $\mathrm{O}$ ultracongelamento é referido como o que mantém os meniscos o mais próximo de sua estrutura a fresco e de menor custo operacional ${ }^{(9,13,14,20,27,28)}$. A preservação por 30 dias, em temperatura de $-73^{\circ} \mathrm{C}$, usada nesta pesquisa, mostrou que o procedimento foi adequado e expresso pela manutenção do tamanho e textura macroscópica dos meniscos.

A fixação do menisco ao receptor pode ser realizada por uma variedade de técnicas operatórias; desde a sutura do corpo e cornos meniscais aos tecidos moles ou por meio da fixação óssea por túneis no platô tibial com ou sem bloco ósseo, mas sempre associado à fixação do menisco na membrana sinovial adjacente $e^{(2,5,6,18,12,27)}$. Independente da cirurgia aberta ou videoassistida, as técnicas são trabalhosas e demandam um tempo operatório considerável para sua consecução. Desse modo, a proposição do uso do adesivo foi aventada para testar a sua eventual efetividade e, em sendo exequível, testar a possível diminuição do tempo operatório, além de outras vantagens técnicas na sua aplicação, principalmente por videoartroscopia, tornando o procedimento mais fácil.
A escolha recaiu sobre a cola de fibrina, uma vez que o uso do cianoacrilato mostrou resultados desfavoráveis em trabalho anterior, onde ocorreu necrose caseosa intraarticular com fístula cutânea ao redor do $15 .^{\circ}$ dia após o implante $\mathrm{e}^{(22,27)}$. A cola de resorcina também se mostrou extremamente danosa para o joelho em coelhos na tentativa de fixação de defeitos osteocondrais da cartilagem articular ${ }^{(28)}$. A cola de fibrina é amplamente utilizada, com resultados favoráveis, em vários procedimentos operatórios e em diversas situações patológicas ${ }^{(23-27)}$. Pela sua disponibilidade, facilidade de aplicação, ausência de rejeição ou reações imunológicas e a capacidade em potencial de manter uma estrutura fibrocartilaginosa, como o menisco, em posição estável, foi uma opção de fixação. Relato de transplante de menisco preservado por ultracongelamento em cães, por meio de sutura ou com o uso de cola de fibrina, mostrou não haver diferenças estatisticamente significantes entre os dois grupos após 12 semanas de observação ${ }^{(26)}$. Os autores analisaram o papel do coágulo de fibrina sobre o processo de reparação na junção menisco-sinovial, ressaltando que o uso de cola de fibrina pode ser útil com o intuito de reduzir a imobilização pós-operatória e facilitar o processo de reabilitação em pacientes transplantados. Apesar dos resultados satisfatórios, não há relatos da continuidade dessa linha de pesquisa. Essa dúvida da literatura foi fator determinante para o início do nosso estudo. Em nosso estudo, o adesivo de fibrina promoveu excelente fixação imediatamente após a sua aplicação, mantendo o menisco com estabilidade adequada aos movimentos de flexoextensão do joelho. Entretanto, a não fixação dos dois cornos dos meniscos à membrana sinovial e/ou tecidos moles da articulação, ou a fixação parcial, foi uma regra nos três tempos de observação (Tabela 1). A fixação total foi uma exceção; desse modo, a eficácia do adesivo de fibrina foi inferior ao da técnica de sutura, com resultados estatisticamente significantes, não coincidindo com os resultados encontrados por Nabeshima et al ${ }^{(26)}$.

A fibrina é tida na literatura como uma substância estimulante do processo cicatricial por ser um produto biológico que está envolvido do processo de reparação tecidual. Em outros tecidos a capacidade de adesividade é associada a essa capacidade de estimular a cicatrização, por isso, a proposição de um trabalho in vivo. Há outra pesquisa em andamento em que as forças de tração, torção e compressão dos meniscos estão sendo testadas ex vivo. Um aparato especial desenvolvido em conjunto com a engenharia mecânica está em fase de testes para medir esses parâmetros. 
A técnica de sutura aos tecidos moles mostrou resultados semelhantes nos três períodos de avaliação e com porcentagem de fixação superior estatisticamente quando comparada com a técnica de adesivo de fibrina. Nossos resultados coincidem com os trabalhos experimentais da literatura, que também mostram alto índice de cicatrização do menisco ao receptor quando do uso da sutura em tecidos moles ${ }^{(9,12,15,18,28)}$.

Os meniscos suturados não mostraram nenhuma alteração da textura de suas superfícies e foram muito semelhantes no aspecto aos meniscos laterais normais em quaisquer dos tempos de observação considerados (Figuras 2 e 3). Por sua vez, os meniscos fixados com fibrina mostraram uma fina camada de secreção amarelada recobrindo sua superfície (Figura 4).

\section{REFERÊNCIAS}

1. Lee DH, Kim TH, Lee SH, Kim SW, Kim JM, Bin SI. Evaluation of meniscus allograft transplantation with serial magnetic resonance imaging during the first postoperative year: focus on graft extrusion. Arthroscopy. 2008;24(10):1115-21.

2. Wirth CJ, Peters G, Milachowski KA, Weismeier KG, Kohn D. Long term results of meniscal allograft transplantation. J Sports Med Am. 2002;30(2):174-81.

3. Yamasaki T, Deie M, Shinomiya R, Yasunaga Y, Yanada S, Ochi M. Transplantation of meniscus regenerated by tissue engineering with a scaffold derived from a rat meniscus and mesenchymal stromal cells derived from rat bone marrow. Artif Organs. 2008;32(7):519-24.

4. Ellingson $\mathrm{Cl}$, Sekija JK. Current opinion in meniscal allograft transplantation. Curr Opin Orthop. 2004;15(2):79-85.

5. Sgaglione NA, Steadman R, Shafter B, Miller MD, Fu FH. Current concepts in meniscus surgery: resection to replacement. Arthroscopy. 2003;19(10):161-88.

6. Felix NA, Paulos LE. Current status of meniscal transplantation. Knee. 2003;10(1): 13-7.

7. Lewinski G. Meniscal allograft transplantation. Orthopade. 2008;37(8):743-8.

8. Cardoso TP. Prótese meniscal de polímero bioabsorvível: estudo em coelhos [tese]. São Paulo: Faculdade de Medicina, Universidade de São Paulo; 2002.

9. Cury RPL, Camargo OPA, Próspero JD, Botter FCS, Severino NR, Aihara T, et al. Transplante homólogo de meniscos: estudo experimental em coelhos. Rev Bras Ortop. 2002;37(8):341-.9.

10. Gelber PE, Gonzáles G, Lloret JL, Reina F, Cáceres E, Monllau JC. Freezing causes changes in the meniscus collagen net: a new ultrastructural meniscus disarray scale. Knee Surg Sports Traumatol Arthrosc. 2008;16(4):353-9.

11. Andersson-Molina H, Karlsson H, Rockborn P. Arthroscopic partial and total meniscectomy: Long-term follow-up study with matched controls. Arthroscopy. 2003;18(2):183-9.

12. Sekiya JK, Ellingson $\mathrm{Cl}$. Meniscal allograft transplantation. J Am Acad Orthop Surg. 2006;14(3):164-74.

13. Reckers LJ. A relação entre diferentes temperaturas e períodos de preservação sobre a celularidade de meniscos de coelhos [tese]. São Paulo: Universidade Federal de São Paulo - UNIFESP; 2004.

14. Reckers LJ, Fagundes DJ, Cohen M, Raymundo JLP, Moreira MB, Paiva VC. Effects of different preservation temperatures and periods menisci cellularity in rabbits. Acta Cir Bras. 2005;20(6):428-33.

15. Sgaglione NA, Steadman R, Shafter B, Miller MD, Fu FH. Current concepts in meniscus surgery: resection to replacement. Arthroscopy. 2003;19(10):161-88.

\section{CONCLUSÃO}

Os nossos resultados mostraram que, ao longo de duas, quatro e oito semanas de observação, os meniscos preservados por ultracongelamento fixam-se de modo mais adequado pela técnica de sutura aos tecidos moles da articulação do joelho de coelhos. Por outro lado, a cola de fibrina, embora fosse isenta de reação inflamatória ou de processo que caracterize rejeição, foi incapaz de manter o menisco fixado ao platô tibial, não sendo assim, como se supunha, uma opção viável para essa cirurgia de transplante.

\section{AGRADECIMENTOS}

Os autores agradecem à Profa. Maria do Carmo Negrini Fagundes pela revisão de português e da versão para o inglês do resumo.

16. Uchio Y, Ochi M, Adachi N, Kawasaki K, Iwasa J. Results of rasping of meniscal tears with and without anterior cruciate ligament injury as evaluated by secondlook arthroscopy. Arthroscopy. 2003;19:463-9.

17. Sohn DH, Toth AP. Meniscus transplantation: current concepts. J Knee Surg. 2008;21(2):163-72.

18. Verdonk PCM, Verstraete KL, Almqvist KF, De Cuyper K,Veys EM, Verbruggen $G$, Verdonk R. Meniscal allograft transplantation: long-term clinical results with radiological and magnetic resonance imaging correlations. Knee Surg Sports Traumatol Arthrosc. 2006;7:1-13

19. Mora G, Alvarez E. Articular cartilage degeneration after frozen meniscus and achilles tendon allograft transplantation: experimental study in sheep. Arthroscopy. 2003;19(8):833-41.

20. Pasa L, Pokorny V, Kalandra S, Melichar I, BilikA. Transplantation of deep frozen menisci._Acta Chir Orthop Traumatol Cech. 2008;75(1):40-7.

21. Fontes CR, Taha MO, Fagundes DJ. Estudo comparativo do uso de cola de fibrina e cianoacrilato em ferimento de fígado de rato. Acta Cir Bras. 2004;19(1):37-42.

22. Reckers LJ, Fagundes DJ, Cohen M, Raymundo JLP, Moreira MB, Paiva VC. Medial meniscus transplantation using cyanoacrylate in rabbits. Acta Cir Bras. 2006;21(2):92-6.

23. Taha MO, Mueller SF, Fraga MM, Rosseto M, Fagundes DJ, Juliano Y, CaricatiNeto A. Morphologic analysis of the fibular nerve repaired with fibrin adhesive. Transplant Proc. 2004;36(2):401-3.

24. Amaral AT, Taha MO, Fagundes DJ. Estudo morfológico das entero-anastomoses com suturas em pontos separados complementados com adesivo sintético ou biológico em coelho. Acta Cir Bras. 2004;19(4):393-405.

25. Fagundes DJ, Taha MO, Rivoire HC. Adesivos cirúrgicos. Revisão e atualização JBM. 2002; 82(3):101-3.

26. Nabeshima Y, Kurosaka M, Yoshiya S, Mizuno K. Effect of fibrin glue and endotelial cell growth factor on the early healing response of the transplanted allogenic meniscus: a pilot study. Knee Surg Sports Traumatol Arthrosc. 1995;3(1):34-8.

27. Reckers LJ, Fagundes DJ, Cohen M. The ineffectiveness of fibrin glue and cyanoacrylate on fixation of meniscus transplantation in rabbits. Knee. 2009;16(4):290-4.

28. von Lewinski G, Milachowski KA, Weismeier K, Kohn D, Wirth CJ. Twenty-year results of combined meniscal allograft transplantation, anterior cruciate ligament reconstruction and advancement of the medial collateral ligament. Knee Surg Sports Traumatol Arthrosc. 2007;15(9):1072-82. 